\title{
Sigmificado, función y solución del odio en jóveness un análisis por sexo
}

\author{
José Luis Valdez Medina* \\ Norma Ivonne González Arratia López Fuentes* \\ Valeria Denisse Arce Valdez* \\ Sonia Cervantes Salazar* \\ Lizbeth Morales Calderón* \\ Mario Piña Monroy* \\ Mario Ulises Maya Martínez**
}

\begin{abstract}
Resumen
El objetivo de la presente investigación consistió en conocer cuál es el significado, la función y la forma de solucionar las situaciones más significativas de odio que han experimentado hombres y mujeres jóvenes a lo largo de su vida. El tipo de estudio es descriptivo, se trabajó con una muestra no probabilística de tipo intencional, compuesta por 400 estudiantes universitarios, cuyas edades oscilan entre los 17 y 23 años, repartidos equitativamente por sexo. Se aplicó un cuestionario que consta de 6 preguntas abiertas que permiten evaluar la concepción y formas de solución del odio en los participantes: ¿qué es el odio?, ¿en qué situaciones surge el odio?, ¿para qué odian las personas?, ¿qué consiguen las personas al odiar?, ¿qué evitan las personas al odiar?, y ¿cómo resuelven las personas una situación de odio? hombres y mujeres definen el odio como un sentimiento de carácter negativo, que genera rencor y que puede llegar a ser expresado o reprimido. Los hombres ven el odio como una reacción psicológica y fisiológica que dirigen al exterior, mientras que las mujeres lo aprecian como un sentimiento que pueden orientar hacia sí mismas, como una cuestión de autodestrucción. Ambos sexos concuerdan en que las posibles soluciones del odio pueden ser aquellas socialmente aceptadas, como la comunicación, la obtención de ayuda, la expresión plena del odio, el amor, la búsqueda de defensas y el olvido de la situación, mientras que otras posibles alternativas que podrían no ser aceptadas como las mejores en el contexto social, serían la agresión y el atentado contra la vida de la persona odiada.
\end{abstract}

\section{Abstract}

The objective of this study was to determine what is the meaning, function and how to solve the most significant situations of hate that have experienced young men and women throughout their lifes. The type of study is descriptive; we worked with a probabilistic sample of intentional type, composed of 400 college students aged between 17 and 23 years, divided equally by sex. We used a questionnaire consisting of 6 open-ended questions to assess the design and solution forms of hatred in the participant: What is hate?, In what situations arises hatred?, Why do people hate?, ¿What get people to hate, What prevents people to hate, and how do the people solves a situation of hate?Men and women report feeling hatred as a negative character, which creates resentment and can be expressed or repressed. Men see hatred as a psychological and physiological reactions that lead to the outside, while women appreciate it as a feeling that can point to themselves, as a matter of self-destruction. Men and women agree that the possible solutions of hatred may be those that are socially accepted, such as communication, getting help, the full expression of hatred, love, the pursuit of defenses and the neglect of the situation, while other possible alternatives that may not be accepted as the best in the social context, would be assault and attempted assassination of the hated person.

*Universidad Autónoma del Estado de México.

**Universidad Xochicalco, Ensenada, Baja California México.

Palabras clave: odio, emoción, obstáculo, autodestrucción, agresión

Keywords: Hate, emotion, obstacle, self-destruction, aggression. 


\section{Introducción}

Desde la aparición del hombre las emociones han estado presentes en su conducta (Abbagnano, 1961), estas constituyen el sistema motivacional humano, que es el que determina y organiza el comportamiento, y pueden tener efectos favorables o desfavorables en las personas (Garrido, 2006). Se trata de fenómenos psicológicos que le dan a la vida su sabor y sus sinsabores, su energía y sentido, dirigen la atención y guían la toma de decisiones, estimulan el aprendizaje y disparan la conducta (Reidl, 2005).

Las investigaciones en torno al tema de las emociones se han encargado de confirmar que los sentimientos negativos se acompañan de algún tipo y nivel de daño, y que las emociones positivas siempre vienen asociadas con algún tipo y nivel de beneficio (Brody \& Ehrlichman, 2000). Las emociones no vienen de la nada, son el resultado de cambios en los modos de organizar la experiencia del mundo y en las formas de enfrentarse a la realidad (Bartolomé, 2006). Una de las emociones básicas del hombre, es el odio, que al igual que el amor, parece ser irracional y puede conducir al individuo a conductas heroicas o malvadas (BBC Mundo, 2008).

Es prácticamente seguro que cada uno de los seres humanos a lo largo de sus vidas, han experimentado una situación de enemistad. Etimológicamente el término odio proviene del latín odium, que significa antipatía y aversión hacia algo o alguien cuyo mal se desea (DRAE, en Colina, 2010).

El odio ha sido tema de análisis para figuras del conocimiento como Aristóteles (quien lo describe en su Retórica oponiéndolo a la ira), David Hume (que lo retoma en su Disertación sobre las pasiones y otros ensayos morales), Freud (que lo esquematiza bajo la conocida formula del odio - amor), hasta llegar entre otros muchos a Ortega y Gasset, quien amparado en la consigna freudiana postula en sus estudios sobre el amor una aproximación bastante cercana a la planteada por la teoría psiquiátrica contemporánea: Odiar a alguien es sentir irritación por su simple existencia, solo satisfaría su radical desaparición (Rodríguez, 2003).

Charles Darwin postula que el origen de esta emoción se encuentra en la venganza y la defensa de los intereses propios. Si se ha sido o se espera ser agredido por otro, ese alguien se convierte en una persona definida por el desafecto que provoca, lo que se transforma en odio. Este sentimiento que como refiere Erich Fromm, es una respuesta a la amenaza de los intereses vitales del hombre (Organización Ecuador Ciencia, 2007).

Para algunos filósofos medievales el odio es el antónimo del amor. El amor es la consonancia de la apetencia respecto de aquello que es aprendido como conveniente, en tanto que el odio es la disonancia del apetito respecto de aquello que se aprende como repugnante o nocivo (Marina \& López, 1999). Este tema fue retomado por Melanie Klein en su descripción del objeto bueno y malo, cuya indiferenciación no permite una clara distinción entre el amor y el odio (Galimberti, 2007), puesto que de acuerdo con Frager \& Fadiman (2001), la Teoría Kleiniana postula que éstos no se pueden separar ya que actúan como fuerzas organizadoras de la psique: la agresión (odio) la divide, mientras que el amor la une.

Actualmente, se entiende que el término odio hace referencia a un sentimiento negativo o de rechazo, que experimenta el individuo como resultado de sus frustraciones (Mora, 1998); que tiende a ser vivido de modo muy intenso e incontrolable, despertando en las personas que lo experimentan una profunda antipatía, disgusto, aversión, antagonismo o repulsión hacia un sujeto, cosa, situación o fenómeno, que las lleva a tener la necesidad de evitar, limitar o destruir aquello que se aborrece (Kaminsky 1990), lo que también definiría al 
odio con una tendencia natural e histórica hacia la violencia (Colina, 2010).

Un estudio realizado en 2008 por científicos británicos de la Universidad de Londres, permitió conocer el mecanismo que hace que los seres humanos aborrezcan a alguien. De acuerdo con los investigadores la zona donde inicia esta emoción está íntimamente ligada al área donde se produce el amor; los resultados demuestran que se activan una serie de circuitos cerebrales en una parte del cerebro que comparte ciertas estructuras con el amor (BBC Mundo, 2008).

El odio a menudo es considerado una pasión malvada que debe ser reprimida, controlada y erradicada, pero para los neurobiólogos e investigadores de la conducta es una pasión tan interesante como el afecto, de ahí la importancia de estudiarlo (BBC Mundo, 2008), además, puede considerarse como una experiencia de tipo universal, puesto que hace referencia a un sentimiento que tiene sus bases $\mathrm{u}$ origen en la capacidad de odiar que forma parte de la condición humana, que se alimenta de sus miedos más tradicionales o heredados por la cultura y de sus pulsiones más primitivas (Marina, 1999), lo que reafirma que se trata de una de las emociones básicas del ser humano.

En este sentido, y de acuerdo con Valdez Medina (2009), puede decirse que el odio surge a partir de la presencia de un obstáculo o de una amenaza que impide conseguir un recurso o satisfactor que se considera un requisito para cubrir una necesidad, una carencia o para evitar alguno de los otros tipos y niveles de miedo que siempre llegan asociados con estas, lo cual interfiere en nuestra posibilidad de sobrevivir en paz y equilibrio, o de adaptarnos con éxito a las condiciones de vida biológicas y psicosocioculturales en las que nos encontramos inmersos.

En otras palabras, el odio puede germinar cuando hay algo que interfiere, se interpone, dificulta o impide que se llegue al total cumplimiento de una expectativa, o bien, cuando se ve alterada o amenazada la posibilidad que tenemos de adaptarnos o de mantener con éxito el estado de paz o equilibrio en el cual es más cómoda nuestra sobrevivencia biológica y/o psicosociocultural.

Con base en esto, algunos autores (Mora, 1998; Valdez Medina, 2009) consideran que el odio es una experiencia muy importante en la vida de los seres humanos, puesto que aunque ha sido visto como un sentimiento negativo que afecta a la vida integral de las personas, también hay que tener en cuenta que se trata de una experiencia necesaria para lograr sobrevivir, debido a que coloca a las personas en una posición de alerta, de escape, de ataque, de repulsión o de rechazo, ante cualquier estímulo que sea juzgado como adverso, que atente o amenace la sobrevivencia biológica $o$ psicosociocultural de los individuos.

Sin embargo, hay que estar pendientes acerca del curso que toma esta experiencia en nuestras vidas, ya que, al no ser solucionada a tiempo, puede llegar a reprimirse y convertirse en un resentimiento, que tiende a generar una amplia gama de conflictos personales, interpersonales y de salud física, que afectan negativamente al desarrollo integral de las personas. Y del mismo modo, siempre se corre el riesgo de que al no solucionarse a tiempo, al igual que como sucede con la culpa, el odio fácilmente pueda llegar a ser utilizado como una forma de control social, puesto que aquél que odia, frecuentemente siente que tiene cierto poder sobre la persona a la que aborrece, pues al poder humillarla, llega a considerar que tiene más fuerza y control sobre ella (Salecl, 2002).

Ahora bien, aunque la posibilidad de poder experimentar odio a lo largo de nuestras vidas es prácticamente total, pues se trata de un fenómeno universal, es importante decir, que es altamente probable que no se experimente del mismo modo si se es hombre (que tiene una mayor tendencia hacia la instrumentalidad), o si se es mujer (que tiene una mayor orientación hacia la expresividad y 
afectividad), debido a que la base biológica y sobre todo psicosociocultural que subyace a los seres humanos y de forma particular a cada uno de los sexos (Díaz Loving, Díaz Guerrero, Helmreich \& Spence, 1981; Fisher, 2003; Valdez Medina, Díaz Loving \& Pérez, 2005), hace que la interpretación de las experiencias tengan diferentes matices que puede ser importante conocer, a fin de entender con mayor precisión lo que hace distintos, pero complementarios a los hombres y a las mujeres.

Con base en lo anterior, el objetivo de la presente investigación consistió en conocer cuál es el significado, la función y la forma de solucionar las situaciones más significativas de odio que han experimentado hombres y mujeres jóvenes a lo largo de su vida.

\section{Método}

La exploración del tema se realizó bajo el enfoque cualitativo y se adoptó el tipo de estudio descriptivo, cuyo propósito de acuerdo con Hernández, Fernández \& Baptista (2008), es seleccionar una serie de cuestiones y medir cada una de ellas independientemente, para así describir lo que se investiga.

\section{Participantes}

Se trabajó con una muestra no probabilística de tipo intencional, compuesta por 400 estudiantes universitarios cuyas edades oscilan entre los 17 y 23 años, repartidos equitativamente por sexo. Todos ellos alumnos de la Universidad Autónoma del Estado de México, ubicada en la ciudad de Toluca.

\section{Instrumento}

Para la recolección de la información, se construyó un cuestionario de seis preguntas abiertas, cuya validez de contenido se obtuvo mediante un análisis de jueces expertos, cuyo índice de consenso o de acuerdo fue mayor al
$80 \%$. Las preguntas son: ¿qué es el odio?, ¿en qué situaciones surge el odio?, ¿para qué odian las personas?, ¿qué consiguen las personas al odiar?, ¿qué evitan las personas al odiar?, y ¿cómo resuelven las personas una situación de odio?

\section{Procedimiento}

Una vez obtenida la autorización de los participantes, se realizó la aplicación del cuestionario de manera individual en las instalaciones de la Universidad Autónoma del Estado de México, con una duración aproximada de 20 minutos.

\section{Resultados}

La evaluación de la información obtenida se realizó mediante el uso de la técnica de análisis de contenido (Álvarez - Gayou, 2003), en tanto que la conformación de las categorías de respuesta se hizo con base en un análisis de jueces, obteniéndose un acuerdo mayor al $85 \%$.

De acuerdo con los resultados obtenidos en la pregunta ¿qué es el odio?, se observa que de manera general, tanto hombres como mujeres lo definen como un sentimiento, una situación desagradable, lo contrario al amor, un sentimiento negativo, de desprecio, represión y agresión. Sin embargo, las diferencias encontradas dejan ver que son ellos quienes puntualizan al odio como una reacción psicológica y fisiológica que dirigen hacia el exterior, en comparación con las mujeres que lo conceptualizan como un sentimiento, sin describirlo detalladamente y que pueden dirigir hacia ellas mismas, como una cuestión de autodestrucción (ver tabla 1). 


\section{Tabla 1}

Definición de odio en hombres y mujeres

\begin{tabular}{|c|c|c|c|c|c|}
\hline \multicolumn{3}{|c|}{ Hombres } & \multicolumn{3}{|c|}{ Mujeres } \\
\hline Dimensión & & Porcentaje & Dimensión & & Porcentaje \\
\hline Sentimiento & $\begin{array}{l}\text { Sentimiento } \\
\text { Euforia } \\
\text { Normal y necesario } \\
\text { Primitivo } \\
\text { Tristeza } \\
\text { Separa sociedades } \\
\text { Celos } \\
\text { Inseguridad } \\
\text { Estado de ánimo } \\
\text { Actitud }\end{array}$ & $17.30 \%$ & Sentimiento & Sentimiento & $8.13 \%$ \\
\hline $\begin{array}{l}\text { Sentimiento } \\
\text { Negativo }\end{array}$ & $\begin{array}{l}\text { Sentimiento } \\
\text { negativo } \\
\text { Maldad } \\
\text { Afecto negativo } \\
\text { Desear el mal } \\
\text { Corrosivo }\end{array}$ & $14.07 \%$ & Sentimiento negativo & $\begin{array}{l}\text { Sentimiento } \\
\text { negativo } \\
\text { Algo que impide ser } \\
\text { feliz } \\
\text { Deseos negativos } \\
\text { Hacia sí mismo }\end{array}$ & $18.98 \%$ \\
\hline $\begin{array}{l}\text { Sentimiento } \\
\text { Reprimido }\end{array}$ & $\begin{array}{l}\text { Rencor } \\
\text { Frustración } \\
\text { Resentimiento } \\
\text { Envidia } \\
\text { Amargura } \\
\text { Sentimiento } \\
\text { reprimido } \\
\text { Desesperación } \\
\text { Remordimiento }\end{array}$ & $15.54 \%$ & Sentimiento reprimido & $\begin{array}{l}\text { Rencor } \\
\text { Frustración } \\
\text { Resentimiento } \\
\text { Envidia } \\
\text { Amargura }\end{array}$ & $20.33 \%$ \\
\hline $\begin{array}{l}\text { Situación } \\
\text { Desagradable }\end{array}$ & $\begin{array}{l}\text { Molestia } \\
\text { Alguien te cae mal } \\
\text { Mala experiencia } \\
\text { Desagrado } \\
\text { Engaño } \\
\text { Traición } \\
\text { Descontento } \\
\text { Disgusto } \\
\text { Problemas } \\
\text { Desacuerdo }\end{array}$ & $12.31 \%$ & Situación desagradable & $\begin{array}{l}\text { Molestia } \\
\text { Situación } \\
\text { desagradable } \\
\text { Algo que disgusta } \\
\text { No cae bien una } \\
\text { persona } \\
\text { Inconformidad hacia } \\
\text { una persona } \\
\text { Mala experiencia } \\
\text { Irritación }\end{array}$ & $20.67 \%$ \\
\hline & $\begin{array}{l}\text { Rechazo } \\
\text { Repulsión } \\
\text { Repudio } \\
\text { No querer a otros } \\
\text { Desprecio } \\
\text { Ignorar }\end{array}$ & & & Rechazo & \\
\hline Desprecio & $\begin{array}{l}\text { Aberración } \\
\text { Sit. Despectiva } \\
\text { No tolerar } \\
\text { Repugnancia } \\
\text { Discriminación } \\
\text { Aversión }\end{array}$ & $19.35 \%$ & Desprecio & Desprecio & $9.93 \%$ \\
\hline
\end{tabular}




\begin{tabular}{|c|c|c|c|c|c|}
\hline $\begin{array}{l}\text { Antónimo } \\
\text { De amor }\end{array}$ & $\begin{array}{l}\text { Contrario al amor } \\
\text { Forma de amor } \\
\text { Pasión }\end{array}$ & $4.39 \%$ & Antónimo de amor & Contrario al amor & $1.01 \%$ \\
\hline Agresión & $\begin{array}{l}\text { Coraje } \\
\text { Hostilidad } \\
\text { Destrucción } \\
\text { Ira } \\
\text { Rabia } \\
\text { Agresión } \\
\text { Enojo } \\
\text { Perjudicar } \\
\text { Dañar } \\
\text { Enfado } \\
\text { Furia } \\
\text { Reacción }\end{array}$ & $12.90 \%$ & & $\begin{array}{l}\text { Coraje } \\
\text { Hostilidad } \\
\text { Destrucción }\end{array}$ & \\
\hline $\begin{array}{l}\text { Reacción } \\
\text { Psicológica }\end{array}$ & $\begin{array}{l}\text { psicológica } \\
\text { Trastorno } \\
\text { Perturbación } \\
\text { Estado mental } \\
\text { Autoprotección } \\
\text { Mecanismo de } \\
\text { defensa }\end{array}$ & $2.34 \%$ & Agresión & $\begin{array}{l}\text { Rabia } \\
\text { Egoismo } \\
\text { Algo que hace daño }\end{array}$ & $21.01 \%$ \\
\hline $\begin{array}{l}\text { Reacción } \\
\text { Fisiológica }\end{array}$ & $\begin{array}{l}\text { Reacción fisiológica } \\
\text { Enfermedad } \\
\text { Impulso } \\
\text { Liberar tensión } \\
\text { Energía }\end{array}$ & $1.75 \%$ & & & \\
\hline
\end{tabular}

$\begin{array}{llll}\text { Total } & 100 \% & \text { Total } & 100 \%\end{array}$

Las respuestas de hombres y mujeres para la pregunta ¿en qué situaciones surge el odio?, se clasificaron en las categorías: situaciones de conflicto, de desagrado, de daño y rechazo, agresión y envidia. Los hombres consideran que el odio aparece como respuesta fisiológica, ante el miedo y en las relaciones interpersonales, mientras que las mujeres argumentan que se origina cuando no se cumplen expectativas, ante el rencor y la vulnerabilidad (ver tabla 2).

Tabla 2.

Situaciones en las que surge el odio en hombres y mujeres.

\begin{tabular}{|c|c|c|c|c|c|}
\hline \multicolumn{3}{|c|}{ Hombres } & \multicolumn{3}{|c|}{ Mujeres } \\
\hline Dimensión & & Porcentaje & Dimensión & & Porcentaje \\
\hline $\begin{array}{l}\text { Situaciones de } \\
\text { conflicto }\end{array}$ & $\begin{array}{l}\text { Situaciones de } \\
\text { conflicto } \\
\text { Problemas } \\
\text { Peleas } \\
\text { Discusión } \\
\text { Diferencias } \\
\text { Riñas } \\
\text { Pleitos } \\
\text { Malas relaciones } \\
\text { Enfrentamiento } \\
\text { Crisis }\end{array}$ & $27.80 \%$ & $\begin{array}{l}\text { Situaciones de } \\
\text { Conflicto }\end{array}$ & $\begin{array}{l}\text { Situaciones } \\
\text { de conflicto } \\
\text { Problemas } \\
\text { Peleas } \\
\text { Discusión } \\
\text { Diferencias } \\
\text { competencia } \\
\text { No hay buena } \\
\text { relación }\end{array}$ & $19.06 \%$ \\
\hline
\end{tabular}




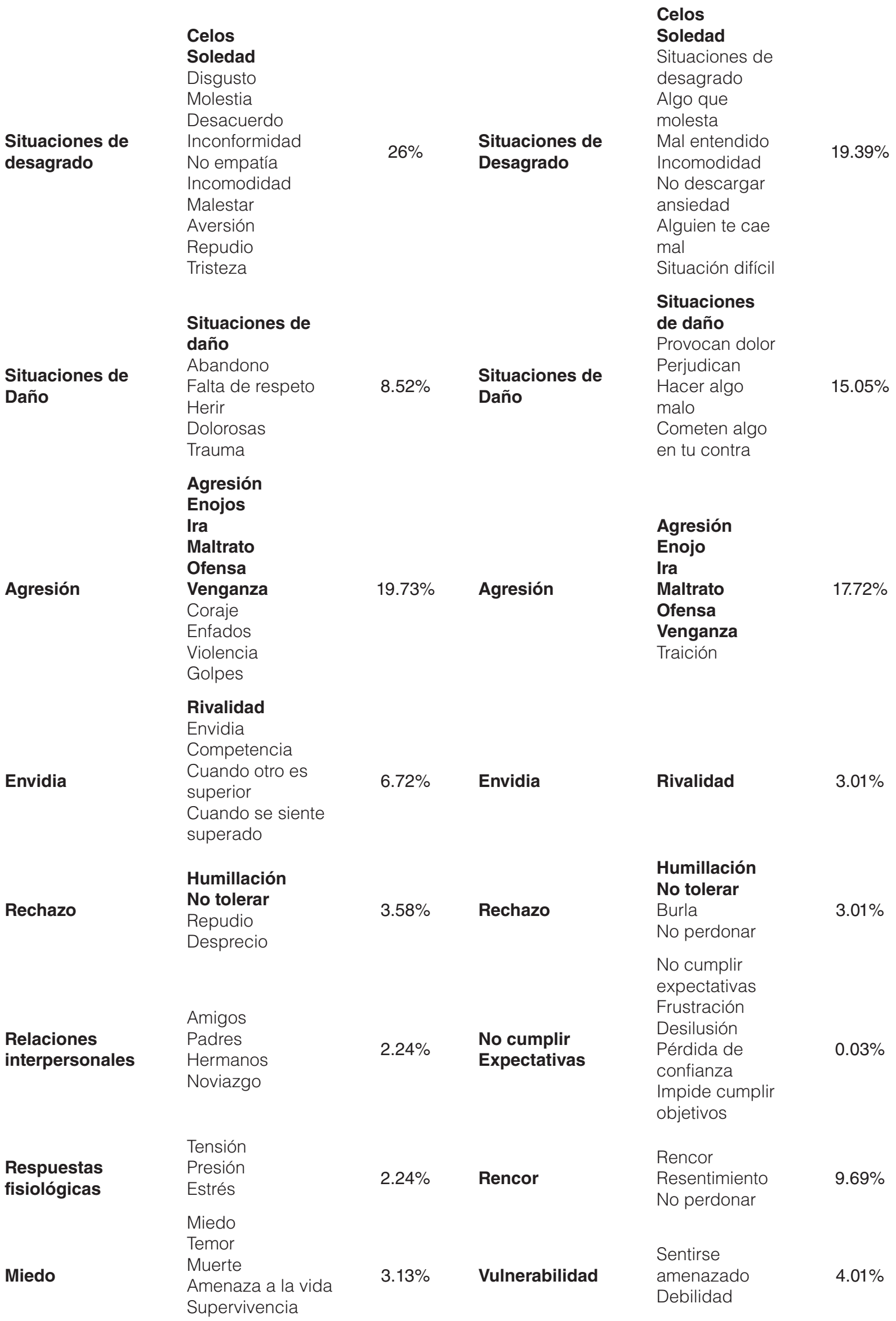

Situaciones de Daño

Agresión

Rechazo
No tolerar

Repudio

esprecio

Amigos

Hermanos

Noviazgo

Tensión

Presión

Miedo

Amenaza a la vida desagrado

molesta

Mal entendido

modidad

No descarga

mal

Provocan dolor

Perjudican

Cometen algo

en tu contra

\section{sión}

Maltrato

Venganza

Traición

\section{Humillación}

Burla

$01 \%$

No cumplir

expectativas

Pérdida de

confianza

Impide cumplir

Resentimiento

$69 \%$

.

\begin{tabular}{llll}
\hline Total & $100 \%$ & Total & $100 \%$ \\
\hline
\end{tabular}


Las categorías obtenidas en hombres y mujeres en la pregunta ¿para qué odian las personas? fueron: sentirse bien, desahogarse, agresión, alejarse, defensa, resentimiento, rechazo y nada. Los hombres aseguran que las personas odian para olvidar, para vivir mal y para ocultar tristeza, es decir, que el odio se convierte en una forma de autodefensa y represión, que se da para culpar al otro; mientras que las mujeres piensan que se emplea para justificarse (ver tabla 3).

Tabla 3.

Principales razones que llevan a hombres y mujeres a odiar.

\begin{tabular}{|c|c|c|c|c|c|}
\hline \multicolumn{3}{|c|}{ Hombres } & \multicolumn{3}{|c|}{ Mujeres } \\
\hline Dimensión & & Porcentaje & Dimensión & & Porcentaje \\
\hline Sentirse bien & $\begin{array}{l}\text { Sentirse } \\
\text { superiores } \\
\text { Sentirse libre } \\
\text { Sentirse diferentes } \\
\text { Sentirse especial } \\
\text { Sentirse } \\
\text { escuchados } \\
\text { Lograr ideales } \\
\text { Porque quieren } \\
\text { Equilibrio } \\
\text { Satisfacer } \\
\text { necesidad } \\
\text { Llamar la atención } \\
\text { Demostrar que } \\
\text { valen } \\
\text { Satisfacer su ego } \\
\text { Orgullo }\end{array}$ & $25 \%$ & Sentirse bien & $\begin{array}{l}\text { Sentirse } \\
\text { superiores } \\
\text { Cubrir carencias } \\
\text { Sentirse seguros } \\
\text { Sentirse } \\
\text { respetados }\end{array}$ & $12.56 \%$ \\
\hline Desahogarse & $\begin{array}{l}\text { Descargar fracaso } \\
\text { Liberar energía } \\
\text { Liberar presión } \\
\text { Liberar amargura } \\
\text { Sacar emociones } \\
\text { Sacar frustración } \\
\text { Sacar impulsos } \\
\text { Descargar culpas } \\
\text { Superar } \\
\text { situaciones } \\
\text { Expresar } \\
\text { sentimientos }\end{array}$ & $22 \%$ & Desahogarse & $\begin{array}{l}\text { Liberar } \\
\text { resentimiento } \\
\text { Sacar coraje } \\
\text { Liberar } \\
\text { sentimientos } \\
\text { Alivio } \\
\text { Disminuir enojo } \\
\text { Expresar } \\
\text { inconformidad } \\
\text { Dar opinión }\end{array}$ & $43.71 \%$ \\
\hline Agresión & $\begin{array}{l}\text { Castigar } \\
\text { Coraje } \\
\text { Furia } \\
\text { Molestia } \\
\text { Vengarse } \\
\text { Destrucción } \\
\text { Lastimar al otro } \\
\text { Perjudicar } \\
\text { Intimidar } \\
\text { Desquitar } \\
\text { Hacer mal } \\
\text { Enojo }\end{array}$ & $11.5 \%$ & Agresión & $\begin{array}{l}\text { Castigar } \\
\text { Desquitarse } \\
\text { Hacer daño } \\
\text { Daño a sí mismo } \\
\text { Tener problemas }\end{array}$ & $21.31 \%$ \\
\hline
\end{tabular}






En los resultados de la pregunta ¿Qué consiguen las personas al odiar?, hombres y mujeres refieren que se obtienen: sentimientos de satisfacción, emociones reprimidas, daño, expresarse, cubrir una necesidad, sentimientos negativos, agresión, soledad, malestar físico y mental, olvido, rechazo y problemas. Al diferenciar entre hombres y mujeres, se encuentra que son ellos quienes consideran que consiguen protección y hacer daño a otros como una forma de representar su fuerza; mientras que ellas solo logran autodestruirse y verse rechazadas por los demás (ver tabla 4). 


\section{Tabla 4}

Consecuencias del odio (lo que se obtiene) en hombres y mujeres

\begin{tabular}{|c|c|c|c|c|c|}
\hline \multicolumn{3}{|c|}{ Hombres } & \multicolumn{3}{|c|}{ Mujeres } \\
\hline Dimensión & & Porcentaje & Dimensión & & Porcentaje \\
\hline Nada & Nada & $16.01 \%$ & Nada & Nada & $4.18 \%$ \\
\hline & $\begin{array}{l}\text { Autoestima } \\
\text { Sentirse bien } \\
\text { Placer } \\
\text { Desquitarse }\end{array}$ & & & $\begin{array}{l}\text { Autoestima } \\
\text { Sentirse bien } \\
\text { Placer }\end{array}$ & \\
\hline $\begin{array}{l}\text { Sentimientos de } \\
\text { satisfacción }\end{array}$ & $\begin{array}{l}\text { Gratificación } \\
\text { Tener la razón } \\
\text { Tranquilidad } \\
\text { Alegría } \\
\text { Disminuir malestar } \\
\text { Alivio }\end{array}$ & $16.72 \%$ & $\begin{array}{l}\text { Sentimientos de } \\
\text { satisfacción }\end{array}$ & $\begin{array}{l}\text { Desquitarse } \\
\text { sentirse fuertes } \\
\text { Tener poder } \\
\text { Elevar su ego } \\
\text { Sentirse superior }\end{array}$ & $19.37 \%$ \\
\hline & $\begin{array}{l}\text { Dolor } \\
\text { Amargarse } \\
\text { Infelicidad } \\
\text { Lastimarse }\end{array}$ & & & $\begin{array}{l}\text { Dolor } \\
\text { Amargarse }\end{array}$ & \\
\hline Dañarse & $\begin{array}{l}\text { Enfermarse } \\
\text { Odio hacia sí } \\
\text { mismos } \\
\text { Ser inútiles }\end{array}$ & $6.40 \%$ & Dañarse & $\begin{array}{l}\text { Sufrimiento } \\
\text { Arruinar su vida }\end{array}$ & $13.35 \%$ \\
\hline $\begin{array}{l}\text { Sentimientos } \\
\text { reprimidos }\end{array}$ & $\begin{array}{l}\text { Frustración } \\
\text { Rencor } \\
\text { Resentimiento } \\
\text { No olvidar } \\
\text { Canalizar su enojo }\end{array}$ & $5.69 \%$ & $\begin{array}{l}\text { Sentimientos } \\
\text { reprimidos }\end{array}$ & $\begin{array}{l}\text { Frustración } \\
\text { Rencor } \\
\text { Resentimiento } \\
\text { Desconfianza }\end{array}$ & $9.68 \%$ \\
\hline & $\begin{array}{l}\text { Desahogo } \\
\text { Liberar tensión } \\
\text { liberar energía } \\
\text { Liberar emoción }\end{array}$ & & & $\begin{array}{l}\text { Desahogo } \\
\text { Liberar tensión } \\
\text { Liberar } \\
\text { pensamientos }\end{array}$ & \\
\hline Expresarse & $\begin{array}{l}\text { Reflejar situación } \\
\text { Hacerlo público } \\
\text { Inconformidad } \\
\text { Descargar furia }\end{array}$ & $8.54 \%$ & Expresarse & $\begin{array}{l}\text { Bajar ansiedad } \\
\text { Demostrar lo que } \\
\text { sienten } \\
\text { Demostrar que }\end{array}$ & $12.30 \%$ \\
\hline $\begin{array}{l}\text { Cubrir una } \\
\text { necesidad }\end{array}$ & $\begin{array}{l}\text { Lograr objetivos } \\
\text { Obtener una cosa }\end{array}$ & $6.40 \%$ & $\begin{array}{l}\text { Cubrir una } \\
\text { necesidad }\end{array}$ & $\begin{array}{l}\text { los han herido } \\
\text { Lograr objetivos }\end{array}$ & $1.04 \%$ \\
\hline $\begin{array}{l}\text { Sentimientos } \\
\text { negativos }\end{array}$ & $\begin{array}{l}\text { Inseguridad } \\
\text { Sentirse mal } \\
\text { Odio } \\
\text { Ira } \\
\text { Coraje } \\
\text { Decepción }\end{array}$ & $8.54 \%$ & $\begin{array}{l}\text { Sentimientos } \\
\text { negativos }\end{array}$ & $\begin{array}{l}\text { Inseguridad } \\
\text { Infelicidad } \\
\text { Irritarse } \\
\text { Envidia }\end{array}$ & $6.28 \%$ \\
\hline & Enemigos & & & & \\
\hline Agresión & Venganza & $5.59 \%$ & Agresión & Enemigos & $10.20 \%$ \\
\hline & $\begin{array}{l}\text { Aislarse } \\
\text { Alejarse de } \\
\text { personas }\end{array}$ & & & & \\
\hline Soledad & $\begin{array}{l}\text { Perder amistades } \\
\text { Incapacidad para } \\
\text { relacionarse }\end{array}$ & $5.33 \%$ & Soledad & Aislarse & $6.54 \%$ \\
\hline
\end{tabular}




\begin{tabular}{|c|c|c|c|c|c|}
\hline Malestar físico & Envejecer & $1.06 \%$ & Malestar físico & $\begin{array}{l}\text { Enfermedad } \\
\text { Somatizar }\end{array}$ & $3.14 \%$ \\
\hline Malestar mental & Estrés & $1.06 \%$ & Malestar mental & $\begin{array}{l}\text { Estrés } \\
\text { Deprimirse } \\
\text { Inestabilidad }\end{array}$ & $2.61 \%$ \\
\hline Olvidar & $\begin{array}{l}\text { Evadir } \\
\text { Evitar }\end{array}$ & $2.49 \%$ & Olvidar & Olvidar & $1.30 \%$ \\
\hline Rechazo & $\begin{array}{l}\text { Desprecio } \\
\text { Discriminación } \\
\text { Ser desplazado } \\
\text { Sentirse incomodo }\end{array}$ & $3.55 \%$ & Rechazo & Ser odiados & $5.75 \%$ \\
\hline Problemas & $\begin{array}{l}\text { Diferencias } \\
\text { conflictos }\end{array}$ & $2.84 \%$ & & & \\
\hline $\begin{array}{l}\text { Hacer daño a } \\
\text { personas }\end{array}$ & $\begin{array}{l}\text { Hacer sufrir } \\
\text { Destruir } \\
\text { Hostilidad }\end{array}$ & $3.55 \%$ & & & \\
\hline & $\begin{array}{l}\text { Seguridad } \\
\text { Autocontrol } \\
\text { Superarse }\end{array}$ & & Problemas & $\begin{array}{l}\text { Diferencias } \\
\text { desacuerdos }\end{array}$ & $4.18 \%$ \\
\hline Protección & $\begin{array}{l}\text { No sentirse tímidos } \\
\text { No ser manipulados } \\
\text { Evitar ser destruido }\end{array}$ & $6.04 \%$ & & & \\
\hline
\end{tabular}

\begin{tabular}{cccc}
\hline Total & $100 \%$ & Total & $100 \%$ \\
\hline
\end{tabular}

Para la pregunta ¿qué evitan las personas al odiar?, las categorías obtenidas en ambos sexos fueron: conflictos, enfrentar la realidad, enfrentarseal problema, expresarse, relacionarse, buscar soluciones, equilibrio interior, seguir con su vida, situaciones desagradables, ser vulnerable, aceptar errores, sentir afectos, ser destruido, perdonar, enfermarse y nada. En cuanto a las diferencias, los hombres consideran que con el odio evitan destruirse a sí mismos, ser rechazados y conocer otras cosas; mientras que las mujeres prescinden de perder tiempo (ver tabla 5).

Tabla 5

Lo que evitan hombres y mujeres al odiar

\begin{tabular}{|c|c|c|c|c|c|}
\hline \multicolumn{3}{|c|}{ Hombres } & \multicolumn{3}{|c|}{ Mujeres } \\
\hline Dimensión & & Porcentaje & Dimensión & & Porcentaje \\
\hline Problemas & $\begin{array}{l}\text { Conflictos } \\
\text { Corajes } \\
\text { Peleas } \\
\text { Disgusto } \\
\text { Rabia } \\
\text { Desagrado }\end{array}$ & $8.92 \%$ & Problemas & $\begin{array}{l}\text { Conflictos } \\
\text { Corajes } \\
\text { Percances }\end{array}$ & $5.51 \%$ \\
\hline $\begin{array}{l}\text { Enfrentar la } \\
\text { realidad }\end{array}$ & $\begin{array}{l}\text { Miedos } \\
\text { Verdad } \\
\text { Reflexión }\end{array}$ & $6.10 \%$ & Enfrentar la realidad & Miedos & $9.44 \%$ \\
\hline $\begin{array}{l}\text { Enfrentarse al } \\
\text { problema }\end{array}$ & $\begin{array}{l}\text { Afrontar } \\
\text { Asumir } \\
\text { responsabilidades }\end{array}$ & $7.51 \%$ & $\begin{array}{l}\text { Enfrentarse al } \\
\text { problema }\end{array}$ & $\begin{array}{l}\text { Enfrentarse al } \\
\text { problema }\end{array}$ & $8.66 \%$ \\
\hline Expresarse & Comunicarse & $2.81 \%$ & Expresarse & Hablar & $2.36 \%$ \\
\hline
\end{tabular}




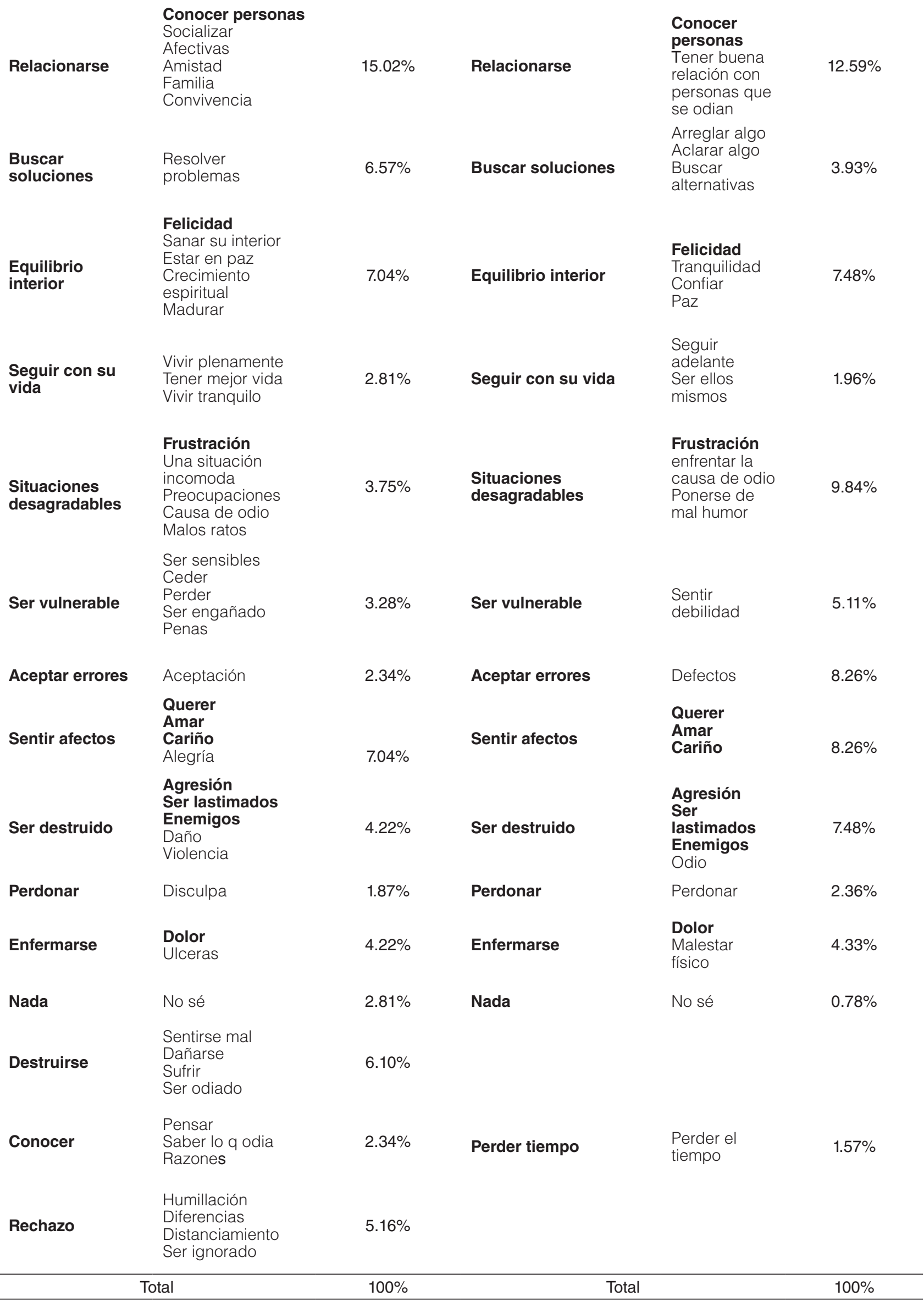


La última pregunta fue: ¿cómo resuelven las personas una situación de odio? Existe concordancia en ambos sexos al afirmar que una situación de odio se resuelve mediante la comunicación, con ayuda, expresando el odio, con agresión, atentando contra la vida, con amor, con defensas, olvidando, razonando, mediante el rechazo, tranquilizándose y con el paso del tiempo. Los hombres obtuvieron dos categorías más en comparación con las mujeres, puesto que consideran que una situación de odio se puede solucionar arreglando las diferencias, o bien, que en realidad no se resuelve (ver tabla 6).

\section{Tabla 6}

Formas de solución del odio en hombres y mujeres

\begin{tabular}{|c|c|c|c|c|c|}
\hline \multicolumn{3}{|c|}{ Hombres } & \multicolumn{3}{|c|}{ Mujeres } \\
\hline Dimensión & & Porcentaje & Dimensión & & Porcentaje \\
\hline Comunicación & $\begin{array}{l}\text { Hablando } \\
\text { Diálogo } \\
\text { Conversando } \\
\text { Escuchando }\end{array}$ & $30.39 \%$ & Comunicación & $\begin{array}{l}\text { Hablando } \\
\text { Discutiendo }\end{array}$ & $37.26 \%$ \\
\hline Con ayuda & $\begin{array}{l}\text { Con psicólogo } \\
\text { Con religión }\end{array}$ & $4.90 \%$ & Con ayuda & Terapia & $1.86 \%$ \\
\hline Expresando odio & $\begin{array}{l}\text { Venganza } \\
\text { desahogándose }\end{array}$ & $7.84 \%$ & Expresando odio & $\begin{array}{l}\text { Venganza } \\
\text { Diciendo lo } \\
\text { que sienten } \\
\text { Haciendo la } \\
\text { vida imposible }\end{array}$ & $16.14 \%$ \\
\hline Agresión & $\begin{array}{l}\text { A golpes } \\
\text { Violencia } \\
\text { Haciendo daño } \\
\text { Gritos } \\
\text { Guerras } \\
\text { Con ira } \\
\text { Hostilidad } \\
\text { Peleas }\end{array}$ & $25.49 \%$ & Agresión & Agresión & $8.69 \%$ \\
\hline $\begin{array}{l}\text { Atentando contra } \\
\text { la vida }\end{array}$ & $\begin{array}{l}\text { Homicidios } \\
\text { Suicidios } \\
\text { Matando }\end{array}$ & $3.43 \%$ & $\begin{array}{l}\text { Atentando contra } \\
\text { la vida }\end{array}$ & Matar & $0.62 \%$ \\
\hline Con amor & $\begin{array}{l}\text { Haciendo amigos } \\
\text { Queriéndose él } \\
\text { Amando a otros }\end{array}$ & $3.43 \%$ & Con amor & $\begin{array}{l}\text { Buenas } \\
\text { acciones }\end{array}$ & $4.96 \%$ \\
\hline Con defensas & $\begin{array}{l}\text { Evitando } \\
\text { despreciando } \\
\text { Rechazando } \\
\text { Evadiendo }\end{array}$ & $2.45 \%$ & Con defensas & Evitando & $4.34 \%$ \\
\hline Olvidando & $\begin{array}{l}\text { Dejarlo de lado } \\
\text { Cortando } \\
\text { vínculos }\end{array}$ & $2.45 \%$ & Olvidando & Olvidar & $6.21 \%$ \\
\hline
\end{tabular}




\begin{tabular}{|c|c|c|c|c|c|}
\hline Razonando & $\begin{array}{l}\text { Siendo realistas } \\
\text { Tomando } \\
\text { conciencia }\end{array}$ & $2.45 \%$ & Razonando & $\begin{array}{l}\text { Buscando } \\
\text { alternativas } \\
\text { Cambiando } \\
\text { necesidad } \\
\text { Cambiando } \\
\text { forma de } \\
\text { pensar }\end{array}$ & $5.59 \%$ \\
\hline Tranquilidad & $\begin{array}{l}\text { Reflexionando } \\
\text { Calma } \\
\text { Meditando } \\
\text { Autocontrol }\end{array}$ & $4.90 \%$ & Tranquilidad & Tranquilidad & $1.86 \%$ \\
\hline Rechazo & $\begin{array}{l}\text { Ignorando } \\
\text { Indiferencia }\end{array}$ & $1.96 \%$ & Rechazo & $\begin{array}{l}\text { Ignorando } \\
\text { Indiferencia }\end{array}$ & $10.55 \%$ \\
\hline Con tiempo & Tiempo & $1.96 \%$ & Con tiempo & Tiempo & $1.24 \%$ \\
\hline $\begin{array}{l}\text { Arreglando } \\
\text { diferencias }\end{array}$ & $\begin{array}{l}\text { Acuerdos } \\
\text { Pactos } \\
\text { Aclarando } \\
\text { Aceptando } \\
\text { Tolerancia } \\
\text { Comprendiendo }\end{array}$ & $5.88 \%$ & Siendo egoísta & $\begin{array}{l}\text { Siendo } \\
\text { egoista }\end{array}$ & $0.62 \%$ \\
\hline
\end{tabular}

\begin{tabular}{ccccc} 
No se resuelve & No se resuelve & $2.45 \%$ & & \\
\hline & Total & $100 \%$ & Total & $100 \%$ \\
\hline
\end{tabular}

\section{DISCUSIÓN}

El odio es un sentimiento incomprendido y menospreciado, cuando uno siente odio lo primero que intenta es reprimirlo y ¿por qué?, sólo porque los demás ven el odio como un sentimiento poco apto para la sociedad, como de un intolerante, ya que se describe con frecuencia como lo contrario del amor o la amistad (Kaminsky 1990).

Mientras que en el amor romántico el amante pocas veces es crítico o juzga a la persona amada, en el contexto del odio, el que odia utiliza su criterio y es calculador para hacer daño, herir o vengarse de la persona odiada (BBC Mundo, 2008).

El odio suele ser desencadenado por una injusticia o una herida narcisista, por una situación traumática o inexplicable. Este elemento disparador activa algo que ya está en la condición humana, convirtiéndose así en un problema cultural, pues en las sociedades donde odiar y ejercitar la venganza es una práctica generalizada, basta una mínima ofensa para despertar una tempestad de odio (Aguinis, 2003).

De acuerdo con los resultados obtenidos, se encontró que hombres y mujeres definen el odio como un sentimiento de carácter negativo, es decir, se trata de una situación desagradable que genera rencor y que puede llegar a ser expresada o reprimida. Puesto que el odio se encuentra cargado de una profunda antipatía, aversión, disgusto, enemistad o repulsión hacia una o más personas, cosas, situaciones o fenómenos, a los que se quiere evitar, limitar o destruir (Salecl, 2002), genera un deseo de destrucción del objeto odiado (Castilla del Pino, 2002; Rodríguez, 2003).

La hostilidad no verbal y conductual se presenta de diferente manera en hombres y en mujeres, estas últimas tienden a expresar su agresión de manera encubierta con más frecuencia que los varones (Mc Gregor \& Davidson, 2000). Los hombres ven el odio 
como una reacción psicológica y fisiológica que dirigen hacia el exterior, en comparación con las mujeres que lo aprecian como un sentimiento, sin describirlo detalladamente, que pueden dirigir hacia sí mismas, como una cuestión de autodestrucción.

Las situaciones que hacen que se genere el odio en hombres y mujeres son aquellas relacionadas con el conflicto, el desagrado, el daño y el rechazo, así como la agresión y la envidia. Y es que el odio en los seres humanos, es una cuestión social y familiar aprendida de experiencias negativas, que se proyectan a todo el género humano, no importando si se es hombre o mujer (Aguinis, 2003).

Los resultados encontrados permiten apreciar que los hombres, a diferencia de las mujeres, consideran que el odio surge ante circunstancias físicas, puesto que ellos ubican el miedo en el exterior; mientras que ellas reprimen más este sentimiento. Las mujeres consideran que el odio se origina cuando no se cumplen expectativas, lo que provoca rencor y hace que la persona experimente vulnerabilidad. Esto puede deberse a lo que establecen Revee (1994), Hupka \& Banco (1996), Valdez-Medina, Díaz Loving \& Pérez Bada (2005), al mencionar que hombres y mujeres actúan conforme a los conceptos de feminidad y masculinidad dominantes en la cultura y que han internalizado, puesto que el género se convierte en la construcción social responsable de las creencias aprendidas sobre el papel tradicional del rol masculino y femenino, que guía incluso, la interpretación que se hace de las emociones.

Hombres y mujeres, en palabras de los jóvenes universitarios, suelen odiar para desahogarse, sentirse bien y alejarse, pero también lo pueden hacer para agredir, defenderse, generar resentimiento y rechazar a los demás. Los hombres afirman que los individuos odian para olvidar y vivir mal, pero también lo hacen para ocultar la tristeza que experimentan; Esto convierte al odio en una forma de autodefensa, que se da para culpar a otro; mientras que las mujeres reconocen que se odia a alguien para justificar algo.

Lo anterior de acuerdo con Miller (1987), se debe a que para las mujeres el sentido de sí mismas y de su propia dignidad está fundado en su capacidad para crear y mantener relaciones, por lo que tienden a proteger la continuidad de la misma. En cambio, los hombres reaccionan de una manera diferente, ya que generalmente tienden a reprimir todas aquellas emociones que la sociedad considera femeninas (Díaz Guerrero, 1982; Revee, 1994).

El odio, además de ser un sentimiento desagradable, también tiene ciertos beneficios y consecuencias para los individuos que lo experimentan, así lo indican los participantes de la investigación. Las personas que odian, consiguen satisfacción, daño para sí mismas, para expresar o reprimir sentimientos; pueden cubrir una necesidad, experimentar agresión, soledad, malestar físico y mental, olvidar las cosas, vivir rechazo y verse inmersas en problemas.

Esto concuerda con lo mencionado por Mora (1998) y Valdez Medina (2009), al considerar que el odio es una experiencia muy importante en la vida de los seres humanos, puesto que aunque ha sido visto como un sentimiento negativo que afecta a la vida integral de las personas, también hay que tener en cuenta que se trata de una experiencia necesaria para lograr sobrevivir, debido a que coloca a las personas en una posición de alerta, de escape, de ataque, de repulsión o de rechazo, ante cualquier estímulo que sea juzgado como adverso, que atente $\mathrm{o}$ amenace la sobrevivencia biológica $\mathrm{o}$ psicosociocultural de los individuos. Es decir, que las situaciones conflictivas pueden ser un contexto muy adecuado para el aprendizaje de estrategias y desarrollo de habilidades de adopción de perspectivas (Smetana, 2005, en Oliva, 2006), o bien, transformarse en generadoras de problemas psicosociales en el individuo (Laursen \& Collins, 1994). 
Siguiendo en esta mismalínea, las diferencias encontradas por sexo demuestran que los hombres consideran que al odiar consiguen protección y hacer daño a otros como una forma de representar su fuerza; lo que puede deberse a que el odio que experimentan hace que se sientan que tiene poder sobre la otra persona, a la cual pretenderán humillar y la percibirán como indefensa para así mostrarse con mayor fuerza y control sobre ella (Salecl, 2002). En tanto que las mujeres refieren que lo que se obtiene al odiar es el rechazo de los demás y la autodestrucción personal, pues como señala Amato (2007), la mujer crece recibiendo una oscura herencia sobre la cual se estructura su personalidad, pensamiento y afectividad, haciendo que las ideas sobre sí misma y las de su género estén impregnadas de emociones contradictorias y de inseguridades.

Dado que la vida se desarrolla con personas, y lo que sucede entre las personas es el principal determinante de lo que ocurra con ellas y el ambiente que les rodea (Atri \& Zetune, 2006), ambos sexos concuerdan en que las posibles soluciones a una situación de odio pueden ser aquellas socialmente aceptables, como la comunicación, la obtención de ayuda, la expresión plena de la emoción, el amor, la búsqueda de defensas, el olvido de la situación, lo que implicaría razonar y tranquilizarse, así como dejar que pase el tiempo; Por otra parte, otras posibles alternativas, que podrían no ser aceptadas como las mejores en el contexto social, serían la agresión y el atentado contra la vida de la persona odiada; es decir, la agresividad encontrada en los individuos es también una forma de expresión de pensamientos, emociones u opiniones, que con el fin de defender las propias necesidades o derechos, atacan, violan el respeto, la autoestima, la dignidad o la sensibilidad de otro (Aguilar, 1987).

A partir de los resultados obtenidos y con base en la teoría de la paz o equilibrio (Valdez Medina, 2009), puede afirmarse que el odio surge porque hay algo o alguien que estorba o impide llegar al satisfactor que cubriría nuestra necesidad o carencia y que evitaría otros tipos y niveles de miedo. La persona tiene dos opciones de enfrentarlo:

a) Resolver el odio. Puede resolverse si se consigue o si no se consigue el satisfactor, y la persona no tiene queja de ello, es decir, acepta o rechaza abiertamente el resultado. En otras palabras, cuando la queja de lo sucedido desaparece, no importando si se obtuvo o no el satisfactor, el odio está resuelto.

b) No resolver el odio. No se resuelve si se consigue o si no se consigue el satisfactor, y la persona sí tiene queja del resultado obtenido. Esta opción implica fingir o aparentar que se acepta lo que en verdad se rechaza o viceversa. Se entra en conflicto, en contradicción y se continúa odiando.

Así pues se entiende que la frustración es la base del odio. La existencia de la queja indica que la amenaza se mantiene presente, y al no haber una solución viable e inmediata que resuelva la situación, fácilmente se puede llevar al sujeto a construir y desarrollar un estado no sólo de odio contra el o los individuos a los que aborrece, sino de resentimiento contra sí mismo al no ser capaz de solucionar lo que está viviendo, y esto último se convierte en lo más riesgoso que puede haber en estos casos (Valdez Medina, 2009).

El odio es una de las emociones básicas del hombre al igual que el amor, parece ser irracional y puede conducir al individuo a conductas heroicas o malvadas (BBC Mundo, 2008); mientras que el amor está orientado de una forma amable, indulgente y constructiva, que protege y conserva la vida, el odio se dirige hacia el lado contrario, generando fuertes tensiones entre aquellos que lo experimentan y que desafortunadamente no siempre pueden resolver de manera favorable (Marina \& López, 1999; Valdez Medina, 2009). 


\section{Referencias}

Abbagnano, N. (1961). Diccionario de Filosofía. México: Fondo de Cultura Económica.

Aguilar, E. (1987). Asertividad: Cómo ser tú mismo sin culpas. México: Pax.

Aguinis, M. (2003). Las redes del odio. Recursos para desactivar la violencia. Buenos Aires: Planeta.

Álvarez Gayou, J.L (2003). Cómo hacer investigación cualitativa: fundamentos y metodología. México: Paidós.

Amato, M. 2007). La pericia psicológica en violencia familiar. Argentina: La Rocca.

Atri \& Zetune, R. (2006). Cuestionario de evaluación del funcionamiento familiar. En Velasco, M. L. y Luna, M. del R. (Comp.). Instrumentos de evaluación en terapia familiar y de pareja (1-27). México: Pax.

Bartolomé, E. (2006). Educación emocional. México: Paidós.

BBC Mundo. (2008). Dónde nace el odio en el cerebro. Recuperado de http://news.bbc.co.uk/hi/spanish/science/newsid_7697000/7697274.stm

Brody N. \& Ehrlichman, H. (2000). Psicología de la Personalidad. España: Prentince Hall.

Castilla del Pino, C. (2002) El odio. Barcelona: Tusquets.

Colina, C. (2010). Las paradojas del odio. Revista Razón y Palabra, 71.

Díaz Guerrero, R. (1982). La psicología del mexicano. México: Trillas.

Frager, R \& Fadiman, J. (2001). Teorías de la personalidad. México: Oxford - Alfaomega.

Galimberti, U. (2007). Diccionario de Psicología. México: Siglo XXI.

Garrido, L. (2006). Apego, emoción y regulación emocional. Implicaciones en la salud. Revista Latinoamericana de Psicología, 38 (3), 493-507.

Hernández, S., Fernández, C. \& Baptista, L. (2008). Metodología de la investigación. México: Mc Graw Hill.

Hupka, R. B. \& Banco, A. L. (1996). Las diferencias de sexo en los celos: ¿Evolución o construcción social? Cross Cultural Research.

Kaminsky, G. (1990). Spinoza la política de las pasiones. Buenos Aires: Gedisa.

Laursen, B. \& Collins, W. (1994). Interpersonal conflict during adolescence. Psychological Bulletin, 115, 197-209.

Marina, J. \& López, M. (1999). Diccionario de los sentimientos. Barcelona: Anagrama.

Mc Gregor, M. \& Davidson, K. (2000). Men's and women's hostility is perceived differently. Journal of research in Personality, 34, 252-261.

Miller, J. B. (1987). Hacia una nueva psicología de la mujer. Boston: Beacon Press.

Mora, F. (1998). Los caminos cerebrales de la emoción y el placer. México: Nobel.

Oliva, A. (2006). Relaciones familiares y desarrollo del adolescente. Anuario de Psicología, 37 (3), 209-223.

Organización Ecuador Ciencia. (2007). Teoría del odio. Recuperado de http://www.ecuadorciencia.org/articulos.asp?id=3232

Reidl, Martínez L. M. (2005). Celos y envidia: emociones humanas. México: UNAM.

Reeve, J. (1994). Motivación y Emoción. Madrid. México: Mc Graw Hill.

Rodríguez, N. (2003). La comunidad del odio. Revista de Estudios Sociales, 16, 94-104.

Salecl, R. (2002). (Per) Versiones de amor y de odio. México: Siglo XXI.

Valdez Medina, J. L. (2009). Teoría de la paz o equilibrio: una nueva teoría que explica las causas del miedo y del sufrimiento, y que nos enseña a combatirlos. México: Edamex.

Valdez Medina, J. L., Díaz Loving, R. y Pérez Bada, M. (2005). Los hombres y las mujeres en México: Dos mundos distantes y complementarios. México: Universidad Autónoma del Estado de México. 